Published in final edited form as:

Strabismus. 2012 September ; 20(3): 109-114. doi:10.3109/09273972.2012.702323.

\title{
Isolated Y-Splitting and Recession of the Lateral Rectus Muscle in Patients with Exo-Duane Syndrome
}

\author{
Federico G. Velez, MD ${ }^{1,2}$, Guillermo Velez, MD³, Karen Hendler, MD ${ }^{1}$, and Stacy L. Pineles, \\ MD ${ }^{1}$ \\ ${ }^{1}$ Jules Stein Eye Institute, University of California Los Angeles \\ 2Olive View UCLA Medical Center, Sylmar, California \\ ${ }^{3}$ University of Antioquia - Private Practice, Medellin, Colombia
}

\begin{abstract}
Purpose-Weakening of both horizontal rectus muscles is performed for patients with Duane syndrome and significant misinnervation of the lateral rectus (LR) muscle resulting in strabismus, limitation to ocular rotations, and globe retraction. In patients with severe up-/downshoots, a Ysplitting of the LR is often recommended. The purpose of this study was to evaluate the efficacy of isolated unilateral LR recession-Y splitting in exo-Duane patients with limitation to adduction and up-/downshoots.
\end{abstract}

Methods-Retrospective review of the records of consecutive patients with exo-Duane syndrome and up/downshoots who underwent isolated Y-splitting-recession of the affected LR.

Results-The records of 10 patients were reviewed (mean age at surgery $23 \pm 21$ years). The Ysplit was performed $10 \mathrm{~mm}$ posterior to the insertion and was combined with a mean LR recession of $8.7 \pm 2.9 \mathrm{~mm}$. Torticollis decreased from $12.7 \pm 4.4^{\circ}$ to $4.8 \pm 5.3^{\circ}(P=0.003)$. Exotropia improved from $18.4 \pm 7.3$ to $6.2 \pm 5.9$ PD postoperatively $(P<0.001)$. Exotropia in contralateral gaze improved from $33.7 \pm 11.8$ to $18.7 \pm 18.1$ PD postoperatively $(P=0.09)$. No significant postoperative changes in esotropia in ipsilateral gaze, vertical deviations, or ocular rotations in adduction or abduction were observed. Downshoots were significantly decreased $(P=0.01)$, and there was a trend toward improvement of upshoots $(P=0.07)$. There were no overcorrections, although 3 patients required additional LR weakening and transposition.

Conclusions-LR Y-splitting-recession improves ocular alignment, torticollis, and up-/ downshoots. LR recession improves ocular alignment and torticollis, while the addition of a Ysplit procedure improves up-/downshoots.

\section{Keywords}

Strabismus; Surgery; Strabismus surgery incisional; Surgery

\section{INTRODUCTION}

Exotropic Duane syndrome is a relatively rare form of Duane syndrome that is often associated with upshoots and downshoots, as well as globe retraction on adduction.

(C) 2012 Informa Healthcare USA, Inc.

Address for Correspondence: Stacy L. Pineles, MD, 100 Stein Plaza, Los Angeles, CA 90095. Phone: 310-267-1007; Fax: 310825-012. pineles@jsei.ucla.edu.

Declaration of interest: None of the authors have any financial conflicts of interest. 
Exotropic Duane syndrome occurs when the force generated by the lateral rectus, either actively through misinnervation or passively through lateral rectus contracture, is greater than the corresponding medial rectus force. If abduction is normal, exotropia can be present due to very strong contraction of the lateral rectus; however, in cases with less than normal abduction, exotropia can still be present due to synergistic divergence, or synergistic abduction: when the patient tries to adduct the affect eye, it abducts instead. ${ }^{1,2} \mathrm{Up}$ - and downshoots commonly occur in patients with Duane syndrome. The etiology of these anomalous movements is debatable. Upshoots and downshoots are likely to occur due to slippage of the shortened lateral rectus muscle superiorly or inferiorly over the crest of the globe on attempted adduction ("bridle effect"). However, other factors that may play a role in the pathogenesis may include co-contraction of the superior or inferior rectus $s^{3,4}$ or instability of connective tissue surrounding the lateral rectus. ${ }^{3}$ To address the slippage of the lateral rectus muscle bridle effect, a Y-splitting procedure of the lateral rectus muscle can be performed by splitting the muscle from its insertion as far posteriorly as possible, spreading the muscle halves $10 \mathrm{~mm}$ above and below the original insertion at the desired recession point. ${ }^{5}$ By splitting the lateral rectus muscle, one removes it from the "crest" of the globe and theoretically eliminates lateral rectus slippage and resultant up-/downshoots. The use of this procedure alone for the treatment of exo-Duane syndrome with up- or downshoot has only been described in case reports and small series of less than 5 patients. ${ }^{5-8}$ The purpose of this study is to describe the outcomes of a relatively larger series of exo-Duane patients with up-/downshoots after combined Y-split and recession of the misinnervated lateral rectus muscle.

\section{METHODS}

This study was approved by the University of California, Los Angeles Institutional Review Board and conformed to the requirements of the U.S. Health Insurance Portability and Accountability act. The clinical records of all patients in a single surgeon practice from 1998-2008 with the diagnosis of exotropic Duane syndrome were retrospectively reviewed. Those subjects who underwent LR Y-splitting recession as their first surgical procedure and had at least 8 weeks of postoperative follow-up were included in the analysis. In brief, our procedure for Y-splitting recessions involves bisecting the lateral rectus muscle from its insertion posteriorly $10 \mathrm{~mm}$. The two halves of the lateral rectus muscle are then sutured 10 $\mathrm{mm}$ above and below the original insertion at the desired recession point (Figure 1). Patients were excluded if there was any history of prior strabismus surgery or bilateral Duane syndrome.

The following preoperative and postoperative characteristics were recorded from the patients' medical record: age at onset, age at surgery, preoperative motor alignment at distance and near and in the cardinal positions of gaze, degrees of torticollis, and an assessment of ocular ductions.

In general, visual acuity was assessed using projected age-appropriate optotypes after a manifest or cycloplegic refraction. Ocular alignment was assessed using cover/uncover and prism and alternate cover testing at distance (20 feet) in the cardinal gaze positions. Motor alignment at near was assessed at 14 inches. All motor evaluations were done using spectacle correction. Torticollis was estimated by the same experienced strabismologist in the patient's habitual head position in degrees. Torticollis was assessed with the subject viewing a distant target. Ocular ductions were measured using a standard 4-point scale. ${ }^{9}$

\section{Statistical Analysis}

Statistical analyses were performed using statistical software, STATA version 10.0 and Microsoft ${ }^{\circledR}$ Excel@. To assess the difference between pre- and postoperative mean 
characteristics, a Student's t-test was used, with a $P<0.05$ considered statistically significant.

\section{RESULTS}

\section{Patient Characteristics}

The records of 10 patients were reviewed. The characteristics of the patients are summarized in Table 1. The patients ranged in age from 6 to 75 years (mean $23 \pm 21$ years). The mean amount of pre-operative exotropia was $18.4 \pm 7.3 \Delta$, and the mean pre-operative torticollis was $12.7 \pm 4.4^{\circ}$ face turn. In general, patients had limitation to both adducting and abducting rotations $(-1.7 \pm 0.9$ and $-1.3 \pm 1.3$, respectively). Eight patients had both upshoots and downshoots, while two patients had upshoots only. The mean amount of lateral rectus recession combined with Y-splitting was $8.8 \pm 3 \mathrm{~mm}$ (range 7-17 $\mathrm{mm}$ ). Postoperatively, there was a statistically significant improvement in torticollis, primary position exotropia, and downshoots (Table 2). There was a trend towards an improvement in upshoots as well $(P=0.07)$. There was a significant decrease in the difference between primary position and ipsilesional gaze $(P<0.001)$ but no significant change in lateral incomitance between primary position and contralesional gaze. There was no significant change in deviations in ipsilateral, contralateral, up- or downgaze. A characteristic patient is depicted in Figures 2 and 3 .

Three of our patients required additional procedures. One of the patients underwent further recession of the ipsilateral lateral rectus muscle with inferior transposition for persistent upshoot and hypertropia. This patient then underwent a subsequent contralateral inferior rectus recess/resect procedure for incomitant hypertropia worst in downgaze. The other two patients underwent contralateral lateral rectus recessions for persistent exotropia (both of these cases presented initially with $25 \Delta$ exotropia and improved to $14 \Delta$ exotropia after the initial surgery). One of these patients underwent two subsequent procedures consisting of a contralateral lateral rectus muscle re-recession and Y-split, and then further recession of the contralateral lateral rectus. After subsequent surgeries, two of the patients were orthotropic, and one demonstrated a residual exotropia measuring $10 \Delta$ and hypertropia of $4 \Delta$.

\section{DISCUSSION}

Y-split combined with recession of the lateral rectus muscle for exo-Duane syndrome has been described both for the treatment of up- or downshoots in eso-Duane syndrome and for exo-Duane syndrome. First described by Jampolsky in 1980 for up- and downshoots, ${ }^{10}$ the procedure addresses lateral rectus contracture and the resultant lateral rectus slippage from the "crest" of the globe that underly up- and downshoots. The goal of lateral rectus Ysplitting-recession in exo-Duane syndrome with up- or downshoots is not only to decrease exotropia and resultant torticollis, but also to decrease up- or downshoots without further limiting in ocular rotations.

In our series of 10 patients, we found a significant improvement in torticollis, primary position deviation, and downshoots without a significant degradation to adducting or abducting rotations. Our results are similar to those of Rao and colleagues, who retrospectively evaluated a smaller group of exo-Duane syndrome patients undergoing Ysplitting recession of the lateral rectus muscle. ${ }^{7}$ In their initial group of 10 subjects undergoing the procedure, 4 had exo-Duane syndrome (the remaining subjects were treated for eso-Duane with marked up- or downshoots). Of the 4 subjects, all had excellent results with an elimination of exotropia, and improvement or elimination of up- or downshoots and torticollis; however no analysis of deviation in side-gazes was performed. Similarly, Rogers and Bremer achieved marked decrease in up- and downshoots in their series of 5 patients 
undergoing Y-splitting of the lateral rectus muscle without concomitant recession. ${ }^{8}$ Although their results were excellent, subsequent authors have advocated for a combined recession of the lateral rectus muscle to address co-contraction, exotropia, and to further enhance the Y-split effect on up- and downshoots by decreasing the effect of lateral rectus muscle contraction and shortening. 5,7

Alternative procedures for exo-Duane syndrome with up- or downshoots include simple lateral rectus recession, combined medial and lateral rectus muscle recessions, ${ }^{11,12}$ lateral rectus posterior fixation sutures,,, 13 and vertical rectus muscle recession combined with lateral rectus recession. ${ }^{14}$ Simple lateral rectus recession has been shown to result in improved primary position deviation and torticollis ${ }^{15}$; however the effect on up- and downshoots has not been well studied. A more aggressive approach to exo-Duane syndrome is to maximally weaken the lateral rectus muscle by disinsertion and fixation to the adjacent periosteal wall. ${ }^{16-18}$ This procedure similarly removes the lateral rectus from the crest of the globe, thereby diminishing slippage and up- or downshoots, and also addresses exotropia. However, this procedure often requires an additional procedure such as medial orbital wall fixation, vertical rectus transposition, or medial rectus recession to avoid a consecutive esotropia.

Three of our patients required additional procedures. Of these 3 patients, 2 were orthotropic after additional procedures, and 1 was left with $10 \Delta$ of residual exotropia (original deviation $25 \Delta$ ). Secondary procedures after Y-splitting lateral rectus recessions for exo-Duane with up- and downshoots used with success in our series consisted of further recession of the ipsilateral lateral rectus muscle with transposition for persistent up- or downshoots and hypertropia, recess/resect procedures on a single muscle for incomitant hypertropia, and contralateral lateral rectus recessions with or without Y-splitting (depending on bilaterality of Duane syndrome) for persistent exotropia. In general, recession of contralateral lateral rectus in any kind of Duane's syndrome is not often advised. Since the contralateral eye is generally dominant, the patient has to increase innervation to the lateral rectus in order to keep the eye in primary position or in abduction. This increased innervation can potentially lead to an increase of the misinnervation of the affected eye's lateral rectus, increasing the anomalous vertical movements and retraction. The exceptions are the rare cases in which the lateral rectus misinnervation is very weak and there is exotropia.

The results of this study must be understood within the context of its limitations. First, it is a retrospective study and is therefore subject to several forms of bias, including selection bias and differential follow-up lengths. In addition, we were unable to select an appropriate control group with which to compare the postoperative results to determine whether a different surgical procedure would have worked equally well or better. Given the retrospective nature of the study, we were unable to evaluate additional interesting associations such as fundus torsion and changes in ocular alignment when moving from various cardinal positions of gaze such as downgaze to downgaze-adduction. Finally, our institute is a tertiary care referral center and we therefore are likely to have accrued a more complex group of patients to study.

In spite of its limitations, this study reveals that isolated Y-splitting recession of the lateral rectus muscle for patients with exo-Duane syndrome and significant up-/downshoots is effective. Overall, the strabismic deviation, torticollis, and up-/downshoots improved significantly without imposing further limitation to abducting and adducting rotations.

\section{Acknowledgments}

Grant support: NIH/NEI K23EY021762 (SLP), Knights Templar Eye Foundation (SLP), Oppenheimer Family Foundation (SLP). 


\section{REFERENCES}

1. Souza-Dias C. Considerações etiopatogênicas sobre a assim chamada "divergência sinérgica. Revista Latino-Americana de Estrabismo. 1979; 3:42.

2. Souza-Dias C. New considerations about Duane's syndrome. Rev Bras Oftalmol. 2009; 68:107.

3. Miller, JM.; Demer, JL.; Rosenbaum, AL. Two mechanisms of up-shoots and down-shoots in Duane's syndrome revealed by a new magnetic resonance imaging (MRI) technique. In: Campos, EC., editor. Strabismus and Ocular Motility Disorders. Proceedings of the Sixth Meeting of the International Strabismological Association. New York, NY: Macmillan Publishing; 1991.

4. Scott AB, Wong GY. Duane's syndrome: an electromyographic study. Arch Ophthalmol. 1972; 87:140. [PubMed: 5057862]

5. Jampolsky, AL. Duane Syndrome. In: Rosenbaum, AL.; Santiago, P., editors. Clinical Strabismus Management. Philadelphia: WB Saunders; 1999.

6. Das JC, Chaudhuri Z, Bhomaj S, Sharma P. Lateral rectus split in the management of Duane's Retraction Syndrome. Ophthalmic Surg Lasers. 2000; 31(6):499-501. [PubMed: 11095130]

7. Rao VB, Helveston EM, Sahare P. Treatment of upshoot and downshoot in Duane syndrome by recession and Y-splitting of the lateral rectus muscle. J AAPOS. 2003; 7(6):389-395. [PubMed: 14730290]

8. Rogers GL, Bremer DL. Surgical treatment of the upshoot and downshoot in Duanes' retraction syndrome. Ophthalmology. 1984; 91(11):1380-1383. [PubMed: 6514307]

9. Mehta, A. Chief complaint, history, and physical examination. In: Rosenbaum, AL.; Santiago, P., editors. Clinical Strabismus Management. Philadelphia, PA: WB Saunders; 1999.

10. Jampolsky, AL. A new surgical procedure for upshoots and downshoots in Duane syndrome: the $Y$ splitting of the lateral rectus. In discussion of paper by Eisenbaum AM, Parks M. In: Jampolsky, AL., editor. A study of various surgical approaches for the leash effect in Duane's syndrome. American Association for Pediatric Ophthalmology and Strabismus. San Diego, CA: 1980.

11. von Noorden GK. Recession of both horizontal recti muscles in Duane's retraction syndrome with elevation and depression of the adducted eye. Am J Ophthalmol. 1992; 114(3):311-313. [PubMed: 1524120]

12. Souza-Dias, C. Additional consequences of muscle co-contraction in Duane's syndrome. In: Souza-Dias, C., editor. Smith-Kettlewell Symposium on Basic Sciences in Strabismus, Guarujá, Brazil. Sao Paulo: Loyola; 1978.

13. Heo H, Park SW. Rectus muscle posterior tenon fixation as an inactivation procedure. Am J Ophthalmol. 2008; 146(2):310-317. [PubMed: 18538301]

14. Mohan K, Saroha V. Vertical rectus recession for the innervational upshoot and downshoot in Duane's retraction syndrome. J Pediatr Ophthalmol Strabismus. 2002; 39(2):94-99. [PubMed: 11911551]

15. Kubota N, Takahashi H, Hayashi T, et al. Outcome of surgery in 124 cases of Duane's Retraction Syndrome (DRS) treated by intraoperatively graduated recession of the medial rectus for esotropic DRS, and of the lateral rectus for exotropic DRS. Binocul Vis Strabismus Q. 2001; 16(1):15-22. [PubMed: 11240932]

16. Andalib D, Javadzadeh A. Lateral rectus muscle disinsertion and reattachment to the lateral orbital wall in exotropic Duane syndrome: a case report. J Med Case Rep. 2008; 2:253. [PubMed: 18662394]

17. Morad Y, Kowal L, Scott AB. Lateral rectus muscle disinsertion and reattachment to the lateral orbital wall. Br J Ophthalmol. 2005; 89(8):983-985. [PubMed: 16024848]

18. Velez FG, Thacker N, Britt MT, et al. Rectus muscle orbital wall fixation: a reversible profound weakening procedure. J AAPOS. 2004; 8(5):473-480. [PubMed: 15492742] 


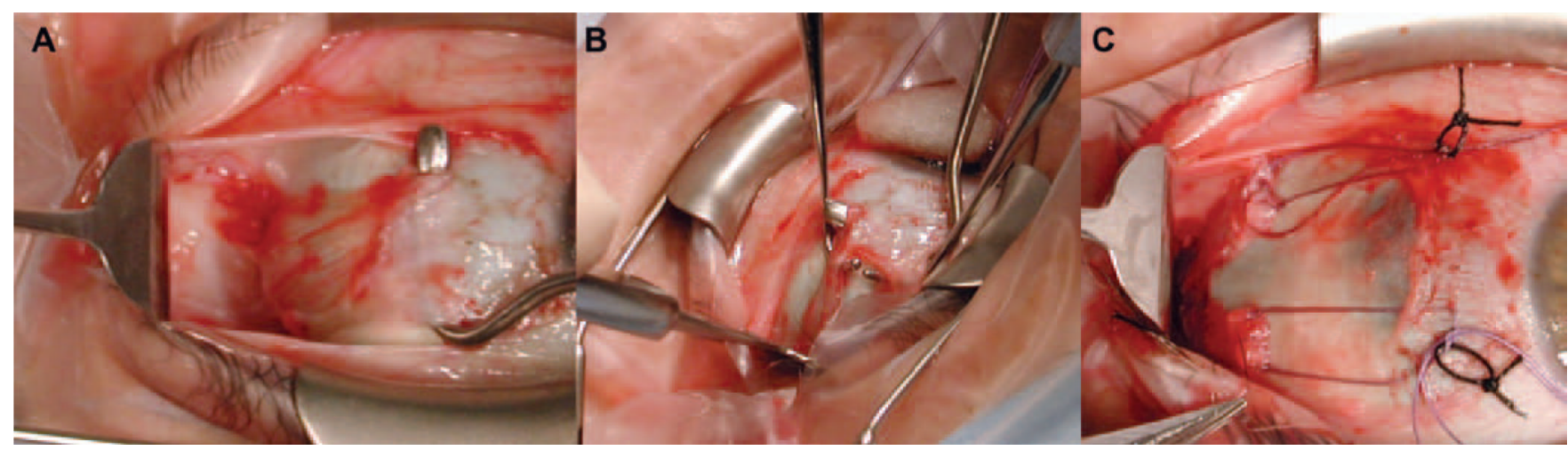

FIGURE 1.

Lateral rectus recession and Y-split for exotropic Duane syndrome. A) The lateral rectus muscle is isolated. B) Hooks are used to split the lateral rectus muscle at least $10 \mathrm{~mm}$ posteriorly. C) The lateral rectus muscle halves are split and recessed by the desired amount. (Note: These photographs were taken from a surgery that was performed using adjustable hang-back sutures. For the patients without adjustable sutures, permanent scleral sutures were used (ie, no hang-backs).) 

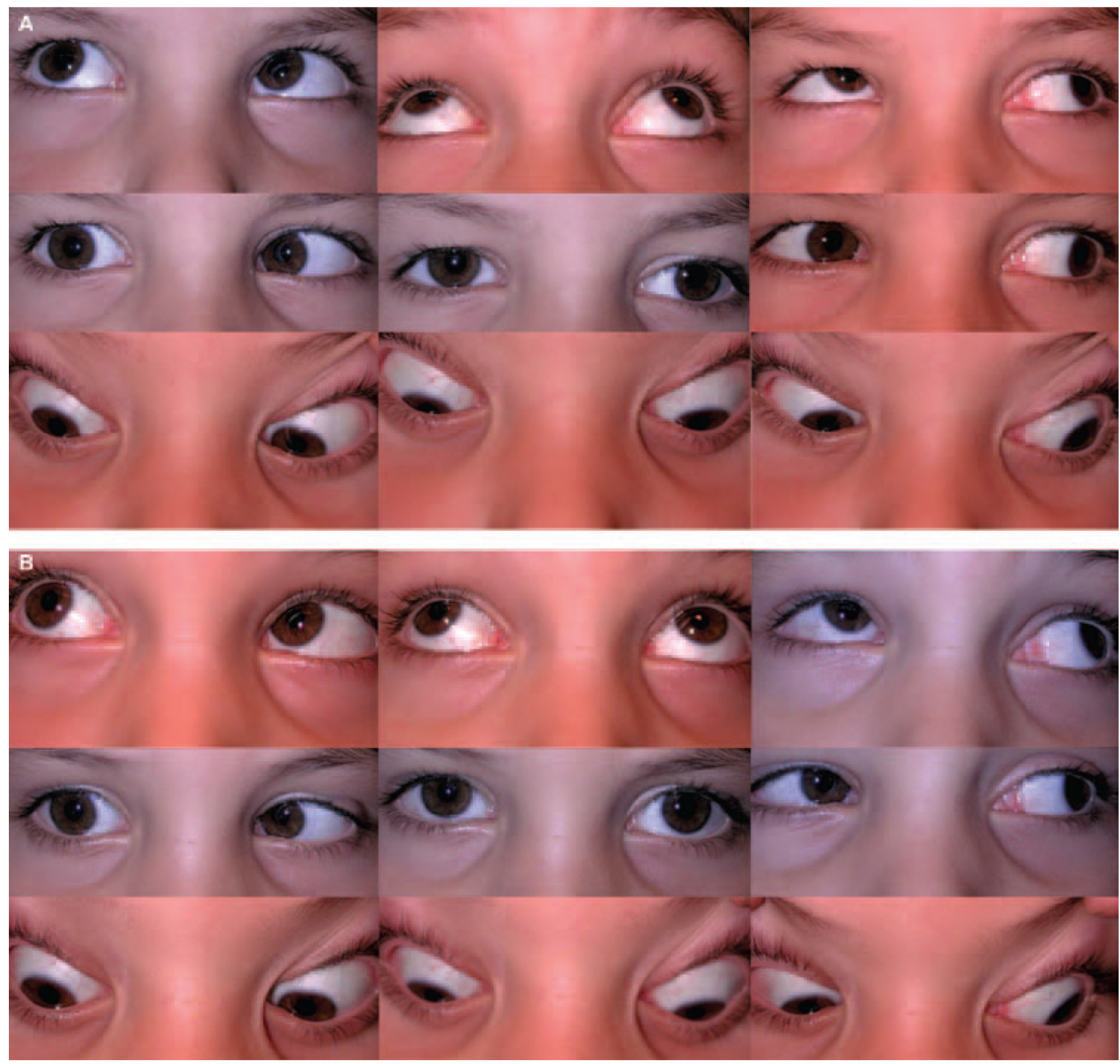

FIGURE 2.

Pre-operative and postoperative photographs of exotropic Duane syndrome patient after Ysplit and recession of the right lateral rectus muscle. A) Pre-operative photographs show exotropia in primary position, a marked upshoot, and limitations to abduction and adduction of the right eye. B) Post-operative photograph shows decreased exotropia in primary position and improvement in the upshoot. 


\section{A}

FIGURE 3.

Pre-operative and postoperative photographs of exotropic Duane syndrome patient after Ysplit and recession of the right lateral rectus muscle. A) Pre-operative photographs show a face turn to the left. B) Post-operative photograph reveals resolution of the face turn. 


\section{TABLE 1}

Pre- and postoperative characteristics of exo-Duane syndrome patients undergoing Y-split combined with recession of the lateral rectus muscle.

\begin{tabular}{|c|c|c|c|}
\hline & Pre-operative & Postoperative & $P$ Value ${ }^{*}$ \\
\hline Torticollis & $12.7 \pm 4.4^{\circ}$ & $4.9 \pm 5.4^{\circ}$ & 0.004 \\
\hline Primary Position Horizontal Deviation & $18.4 \pm 7.3 \Delta \mathrm{XT}$ & $6.2 \pm 6 \Delta \mathrm{XT}$ & $<0.001$ \\
\hline Primary Position Vertical Deviation & $2.2 \pm 4.0 \mathrm{HT}$ & $1.8 \pm 3.8 \Delta \mathrm{HT}$ & 0.8 \\
\hline Adduction & $-1.7 \pm 0.9$ & $-1.3 \pm 1.1$ & 0.5 \\
\hline Abduction & $-1.3 \pm 1.3$ & $-1 \pm 1.5$ & 0.8 \\
\hline Upshoot & $2.2 \pm 0.7$ & $1 \pm 1.6$ & 0.07 \\
\hline Downshoot & $1.9 \pm 1.2$ & $0.2 \pm 1.6$ & 0.02 \\
\hline Lateral Incomitance (Difference between deviation in primary position and ipsilesional gaze) & $22.7 \pm 8.7$ & $5.9 \pm 8.9$ & $<0.001$ \\
\hline $\begin{array}{l}\text { Lateral Incomitance (Difference between deviation in primary position and contralesional } \\
\text { gaze) }\end{array}$ & $-12.3 \pm 13.4$ & $-6.9 \pm 17.4$ & 0.45 \\
\hline
\end{tabular}

* Student T-test.

XT: exotropia, HT: hypertropia. 


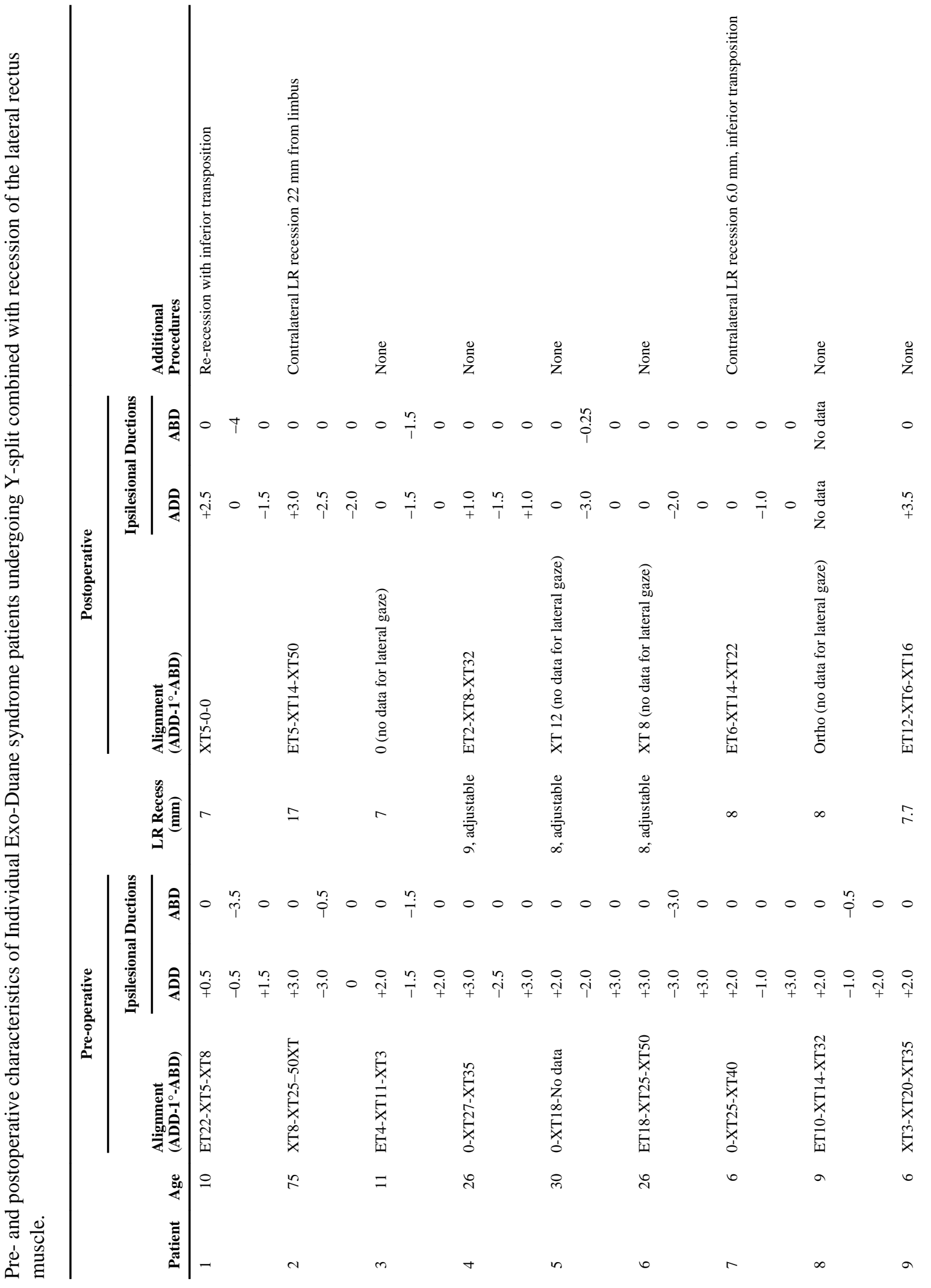




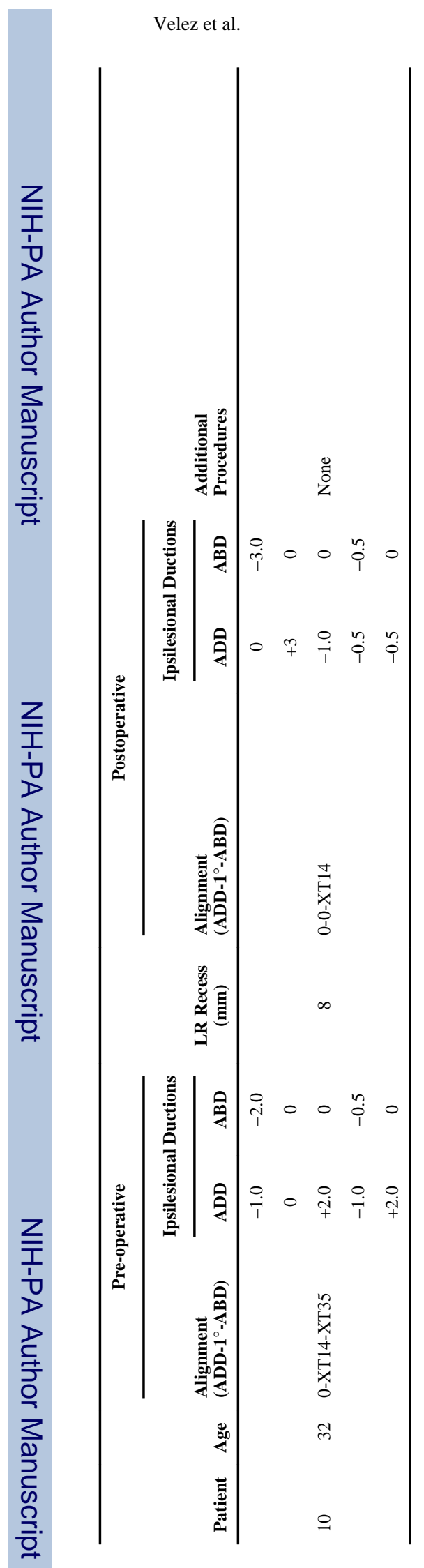

Page 11 